\title{
Evidence of simian virus 40 infection in multiple organ transplant recipients with renal dysfunction
}

\author{
BAHMAN ABEDI KIASARI ${ }^{1,2}$, PAMELA J. VALLELY ${ }^{2}$, CAROLINE E. CORLESS ${ }^{3}$, \\ ALAN CURRY ${ }^{4}$, HILARY COTTERILL ${ }^{4}$, JOHN MURRAY ${ }^{5}$, SHEILA RAMJUG ${ }^{6}$ \\ \& PAUL E. KLAPPER ${ }^{2,4}$
}

From the ${ }^{1}$ Human Viral Vaccine Department, Razi Vaccine E Serum Research Institute, Hesarak, Karaj, Iran, ${ }^{2}$ Virology, Genomic Epidemiology Research Group, School of Translational Medicine, University of Manchester, Manchester, ${ }^{3}$ Department of Microbiology, Royal Liverpool University Hospital, Liverpool, ${ }^{4}$ Clinical Virology, Manchester Medical Microbiology Partnership, Manchester Royal Infirmary, Manchester, ${ }^{5}$ The Haematology Transplant Unit, Christie NHS Foundation Trust, Withington, Manchester, and ${ }^{6}$ Cardiology and Cardiothoracic Surgery, University Hospital of South Manchester, Wythenshawe Hospital, Manchester, UK

\begin{abstract}
Electron microscopy (EM), real-time polymerase chain reaction (PCR) and conventional PCR were used to identify viruses associated with infection in 2 transplantation patients. An autologous haematopoietic stem cell, liver and renal transplant recipient was found to be positive for simian virus 40 (SV40). Dual BK virus and SV40 infection was found in a heart and renal transplantation patient. SV40 infection can occur in immunocompromised patients.
\end{abstract}

Keywords: Polyomavirus, SV40, PCR, real-time PCR, transplantation patients, renal dysfunction

\section{Introduction}

Simian virus 40 (SV40) was originally thought to have been introduced to the human population by contaminated vaccines produced in monkey cells that were naturally infected with SV40. Several subsequent studies have investigated SV40 infection in humans and its potential role in oncogenesis $[1,2]$. Serologic investigations including individuals who are too young to have received the contaminated vaccines showed that $1.3 \%$ to $15.6 \%$ of immunocompromised and immunocompetent patient sera have antibodies to SV40 [3]. This suggests that SV40 circulates in the human population. However, the significance of human infections caused by SV40 remains unknown.

We present 2 cases of transplant patients with SV40 infection; one was also positive for BK virus (BKV) DNA.

\section{Materials and methods}

Electron microscopy (EM)

Specimens were examined using a Phillips EM420 or a Phillips CM10 electron microscope (FEI-Philips, Hillsboro, OR, USA) at magnifications of 62,500 and 46,000 , respectively. Digital images were recorded at 92,000 magnification.

Real-time polymerase chain reaction (PCR) assay

Nucleic acid was extracted from samples according to the manufacturer's instructions using the BioRobot $\mathrm{MDx}$ and Blood BioRobot MDx kit (Qiagen Ltd, Crawley, West Sussex, UK) and stored at $-20^{\circ} \mathrm{C}$ until use. Samples were analysed using BK-specific primers and probe (BKF, 5'-CAGAGGGAAAGTCTTTAGGGTCTTCT-3'; BKR, 5'-CCTTTAATGAAAAATGGGATGAAGATT3'; BKVT, 5'-AAGAAGCAAC

Correspondence: B. Abedi Kiasari, Human Viral Vaccine Department, Razi Vaccine \& Serum Research Institute, Hesarak, Karaj, Iran. Tel: +98 9122190406. E-mail: babedik@yahoo.com; b.abedikiasari@rvsri.ir 
AGCAGATTCTCAACACT-3'). Amplification was performed on the ABI 7500 real-time PCR 'fast' system using a 2-stage thermal profile of $95^{\circ} \mathrm{C}$ for $20 \mathrm{~s}$, followed by 45 cycles of $95^{\circ} \mathrm{C}$ for $3 \mathrm{~s}$ then $60^{\circ} \mathrm{C}$ for $30 \mathrm{~s}$.

\section{Conventional PCR assay}

Urine and blood samples were analysed by PCR using PEP1/PEP2 primers for BKV and JC virus (JCV) and 5 sets of previously described primers (PYVF/PYVR, T3/T4, TA1/TA2, LA1/LA2 and RA1/RA2) targeting different regions of viral genome including regulatory region, $\mathrm{T}$ Ag and VP1 genes for SV40 $[1,4,5]$. KI virus (KIV) and WU virus (WUV) PCR assays were performed on each sample as previously described [6].

\section{Restriction enzyme analysis}

The PCR products from PYVF/PYVR assay were digested with restriction enzyme BamH1 and Hinf1 overnight at $37^{\circ} \mathrm{C}$. The digests were analysed by $2 \%$ agarose electrophoresis.

\section{Sequencing}

PCR amplified fragments were sequenced using the Big Dye Terminator Cycle Sequencing kit (Applied Biosystems UK Ltd) on an ABI 3100 Genetic Analyzer. Contiguous sequences were assembled using Sequencher software version 4.6 (Gen Codes Corporation, Ann Arbor, MI, USA). Sequences were then aligned, followed by removal of mismatches and erroneous peaks. To identify virus-specific sequences a Blast search (NCBI) was performed on GenBank.

\section{Results \\ Patient characteristics}

Case 1 was born in April 1951. In 1993, she was diagnosed with stage IVB Hodgkin's disease. Pleural, lung, and bulky mediastinal disease was noted. An autologous stem cell transplantation was performed in 2000. She received a second autologous stem cell transplant in 2001. Hepatic graft-versushost disease occurred post-transplantation. In 2005, further hepatic impairment was noted and she underwent liver transplantation. She went on to develop kidney and adrenal failure and underwent renal transplantation. Three years after transplantation, she presented bilateral oedema. A renal ultrasound showed no evidence of obstruction and
2 normal-sized kidneys with mild bilateral echogenicity. A renal scan was normal. Serum creatinine and urea were $400 \mu \mathrm{mol} / 1$ and $25 \mathrm{mmol} / \mathrm{l}$, respectively. Urine analysis revealed $4+$ albuminuria. Her immunosuppressive regimen consisted of tacrolimus ( $4 \mathrm{mg}$ twice daily) and prednisolone $(5 \mathrm{mg}$ twice daily). After the diagnosis of renal dysfunction, her tacrolimus and prednisolone doses were reduced (2.5 mg twice daily). She declined renal biopsy. Polyomavirus infection was diagnosed using PCR. She received 4 doses of cidofovir $(0.5 \mathrm{mg} / \mathrm{kg}$ per dose every 2 weeks) and after these interventions, the patient's renal function showed modest improvement. She had no haematuria and the levels of creatinine and urea in serum were $100 \mu \mathrm{mol} / 1$ and $8-9 \mathrm{mmol} / \mathrm{l}$, respectively. Viruria was resolved and renal function remained stable at 6 months post-therapy. There was no report of bacterial or other viral infection.

The second patient was born in July 1968. In August 1988 she underwent orthotopic heart transplantation for puerperal cardiomyopathy after the birth of her first child. She made good progress posttransplant until 2003 when she developed increasing shortness of breath. Investigations performed demonstrated diffuse and distal coronary artery disease with severely impaired left ventricular function. She was also noted to have developed significant renal impairment over this period. Subsequently the patient underwent a combined second orthotopic heart and kidney transplant in November 2003. The patient made a good recovery and was discharged home after 1 month. In the 3 months prior to the detection of SV40, she had frequent episodes of suprapubic discomfort and dysuria. Renal ultrasound and scan were normal and a magnetic resonance angiography was unremarkable. Serum creatinine and urea were $300 \mu \mathrm{mol} / \mathrm{l}$ and $20 \mathrm{mmol} / \mathrm{l}$, respectively. Urine analysis revealed $2+$ albuminuria. There was no evidence of haematuria. Renal impairment and also recurrent urinary tract infection (UTI) were diagnosed. Her immunosuppressive regimen consisted of cyclosporine (40 $\mathrm{mg}$ twice daily), mycophenolate (1 mg twice daily) and prednisolone ( $7.5 \mathrm{mg}$ twice daily). Her immunosuppressive therapy was reduced. The new immuno suppressive regimen consisted of cyclosporine (20 mg twice daily) and prednisolone (2.5 mg twice daily). The patient declined renal biopsy. Polyomavirus infection was diagnosed using the PCR assay. She received 2 doses of cidofovir $(0.5 \mathrm{mg} / \mathrm{kg}$ per dose every 3 weeks). She had good renal function $1 \mathrm{y}$ after transplantation (serum creatinine 90 $\mu \mathrm{mol} / \mathrm{l})$. There was no report of viruria. Routine urine microscopy revealed no bacterial infection, and abdominal imaging was unremarkable. 


\section{Detection of polyomavirus by EM}

Negatively stained urine samples were examined by transmission electron microscopy (TEM). In both cases spherical, non-enveloped virus particles $40 \mathrm{~nm}$ in diameter were identified, showing the morphology characteristic of polyomavirus (Figure 1).

\section{Real-time PCR assay}

Urine samples from each patient were subsequently examined by real-time PCR for BKV and JCV. BKV DNA was detected at low level (706 copies/ml) only in patient 2 .

Viral identification by conventional PCR and restriction enzyme

Urine and blood samples were separately examined by conventional PCR for JCV, BKV, SV40, KIV, and WUV. Samples from patient 1 were negative in the JCV/BKV PCR assay, but positive in the SV40 PCR assays. Samples from patient 2 were positive in both JCV/BKV and SV40 PCR assays. KIV and WUV PCR assays were negative in both patients' samples. PCR products analysed by BamH1 were uncleaved (characteristic of BKV PCR products), whereas products treated by Hinf1 were cleaved into the 110-, 54-, and 4-bp fragments characteristic of SV40.

\section{Sequence analysis}

The DNA fragments of all PCR assays were sequenced in both directions. For patient 1 , sequences

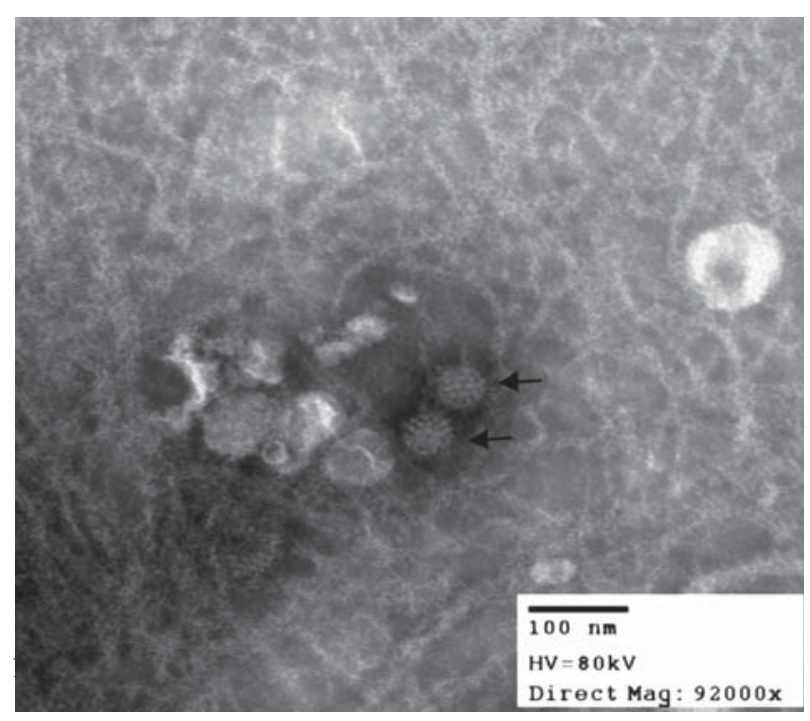

Figure 1. Morphology of polyomavirus particles after negative staining. Spherical and non-enveloped virus particles of approximately $40 \mathrm{~nm}$ in diameter are shown. were $98-100 \%$ identical to the published sequences of SV40 and for the second patient, sequences revealed $99 \%$ similarity with the published respective sequences ofboth SV40 (AF316139.1;AF332699.1;AF316141.1; AF155359.1; AF155358.1; AF156107.1) and BKV (AB269823; AB269848; V01108) in GenBank. SV40 DNA sequences from patient 1 showed 4 point mutations compared to the positive control sequences (partial LT Ag: at nucleotides 2824 and 3000; partial VP1: at nucleotides 2287 and 2379). SV40 DNA sequences from patient 2 exhibited 3 deletions (LT-Ag: at nucleotides 2938 and 2939; VP1: at nucleotide 2297) and 3 point mutations (LT-Ag: at nucleotides 2743; VP1: at nucleotides 2404 and 2476) compared to the positive control sequences (Figure 2).

\section{Discussion}

Molecular evidence of SV40 infection was found in 2 transplantation patients. The diagnosis of polyomavirus was made after TEM examination of urine. The usual threshold of sensitivity of TEM is about $10^{7}$ particles per ml. However, no JC or BK virus DNA was detected in patient 1 by real-time PCR, and only a low level (706 copies $/ \mathrm{ml}$ ) of BKV DNA was detected in patient 2. Using conventional PCR followed by restriction enzyme analysis and sequencing, patient 1 was found to be positive for SV40, and patient 2 was found to be positive for both BKV and SV40. In case 2, the low level of BKV DNA (706 copies/ml) implies that most of the virus was SV40. This is confirmed by the PCR results, in that SV40 was more readily amplified from the samples than BK virus when using conventional PCR. The risk of false-positive results due to contamination by common laboratory plasmids containing SV40 sequences has been reported [7]. To avoid or reduce this risk, 5 separate regions of the viral genome (in total $1565 \mathrm{bp}$ ) were amplified. They contain a 172-bp fragment of the N-terminus of SV40 large $T$ antigen gene (PCR assay using PYVF/PYVR primers), a $441 \mathrm{bp}$ fragment of the C-terminus of SV40 large $T$ antigen gene (PCR assay using TA1/TA2 primers), a $344 \mathrm{bp}$ fragment of the large $\mathrm{T}$ antigen gene (PCR assay using T3/T4 primers), a $294 \mathrm{bp}$ fragment of the VP1 gene (PCR assay using LA1/LA2 primers) and a $314 \mathrm{bp}$ fragment of the regulatory region (PCR assay using RA1/RA2 primers). DNA sequencing data from all 5 PCR fragments confirmed the identity of SV40 detected. To prevent PCR contamination, general laboratory procedures were strictly performed. Furthermore, re-testing the positive samples with the same PCR conditions produced identical results, indicating no variability in the assay. Contamination by the plasmid template is also unlikely because water controls were consistently negative and 
A

Control776

sample 001 sample 002 sample 003

sample 004

Control776

sample 001 sample 002 sample 003 sample 004

Control776

sample 001 sample 002 sample 003 sample 004

Control776

sample 001 sample 002 sample 003 sample 004

Control776

sample 001 sample 002 sample 003 sample 004

Control776

sample 001 sample 002 sample 003 sample 004

Control776 sample 001 sample 002 sample 003 sample 004

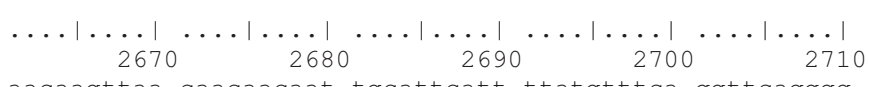

aacaagttaa caacaacaat tgcattcatt ttatgtttca ggttcagggg

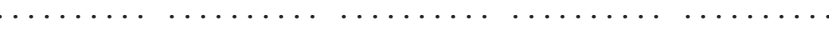

$\ldots \ldots \ldots \ldots \ldots \ldots \ldots \ldots \ldots$

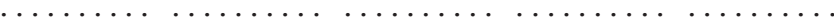

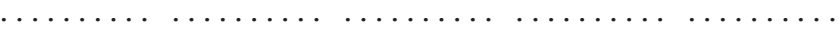

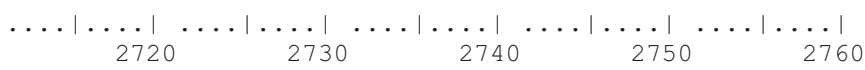

gaggtgtggg aggtttttta aagcaagtaa aacctctaca aatgtggtat

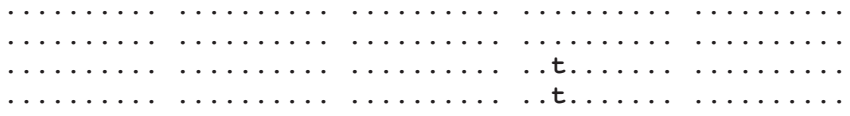

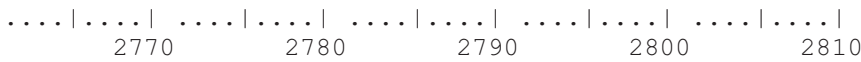
ggctgattat gatcatgaac agactgtgag gactgagggg cctgaaatga

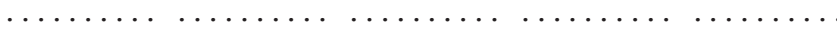

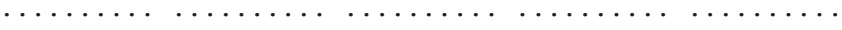

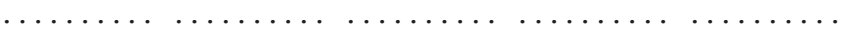

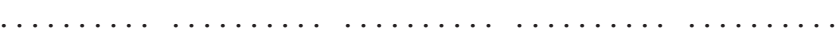

$\left.\left.\left.\left.\ldots|\cdots|\right|_{2820} \ldots|\cdots|\right|_{2830} \ldots|\cdots|\right|_{2840} \ldots|\cdots|\right|_{2850} \ldots|\cdots|$

gccttgggac tgtgaatcaa tgcctgtttc atgccetgag tcttccatgt

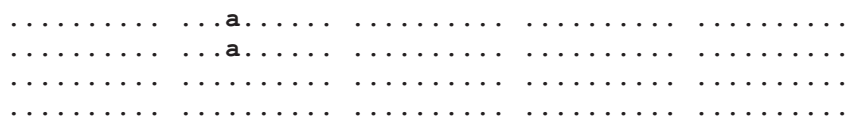

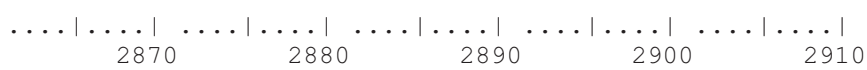

tcttctccc accatcttca tttttatcag cattttcctg getgtcttca

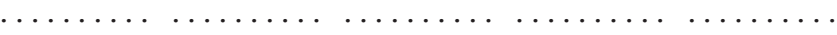

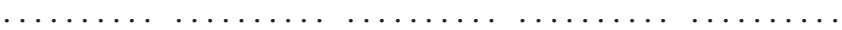

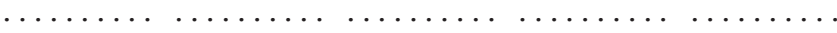

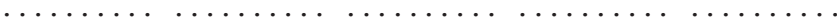

$\ldots|\ldots| \ldots|\ldots| \ldots|\ldots| \ldots|\ldots| \ldots|\ldots| \ldots|\ldots|$ $2920 \quad 29300_{2940}{ }_{2950}{ }^{\cdots}{ }_{2960}$ tcatcatcat cactgtttct tagccaatct aaactccaa ttcccatagc

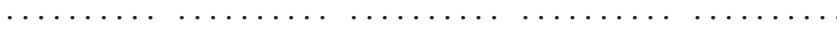

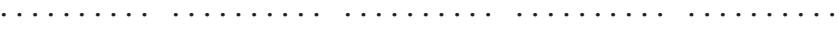

$\ldots \ldots \ldots \ldots \ldots \ldots \ldots \ldots \ldots \ldots \ldots \ldots \ldots$

$\ldots \ldots \ldots \ldots \ldots \ldots \ldots \ldots \ldots \ldots$

$\ldots|\ldots| \ldots|\ldots| \ldots|\ldots| \ldots|\ldots| \ldots|\ldots| \ldots|\ldots| \ldots \mid$

cacattaaac ttcatttttt gatacactga caactaaac tctttgtcca

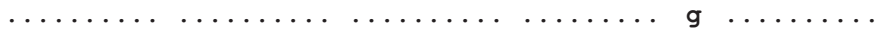

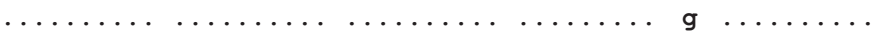

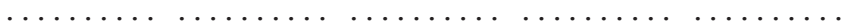

.

Figure 2. Nucleotide sequences of the partial large T antigen (T-Ag) (A) and the partial VP1 (SV40 VP1 PCR assay) (B) of simian virus 40 (SV40) isolate sequences compared to positive control. Each sample is identified on the left (positive urine and blood samples from patient 1: 001-002; positive urine and blood samples from patient 2: 003-004). Dots indicate identity and dashes indicate a deletion compared to the sequence of positive control, which is given on the top line. 


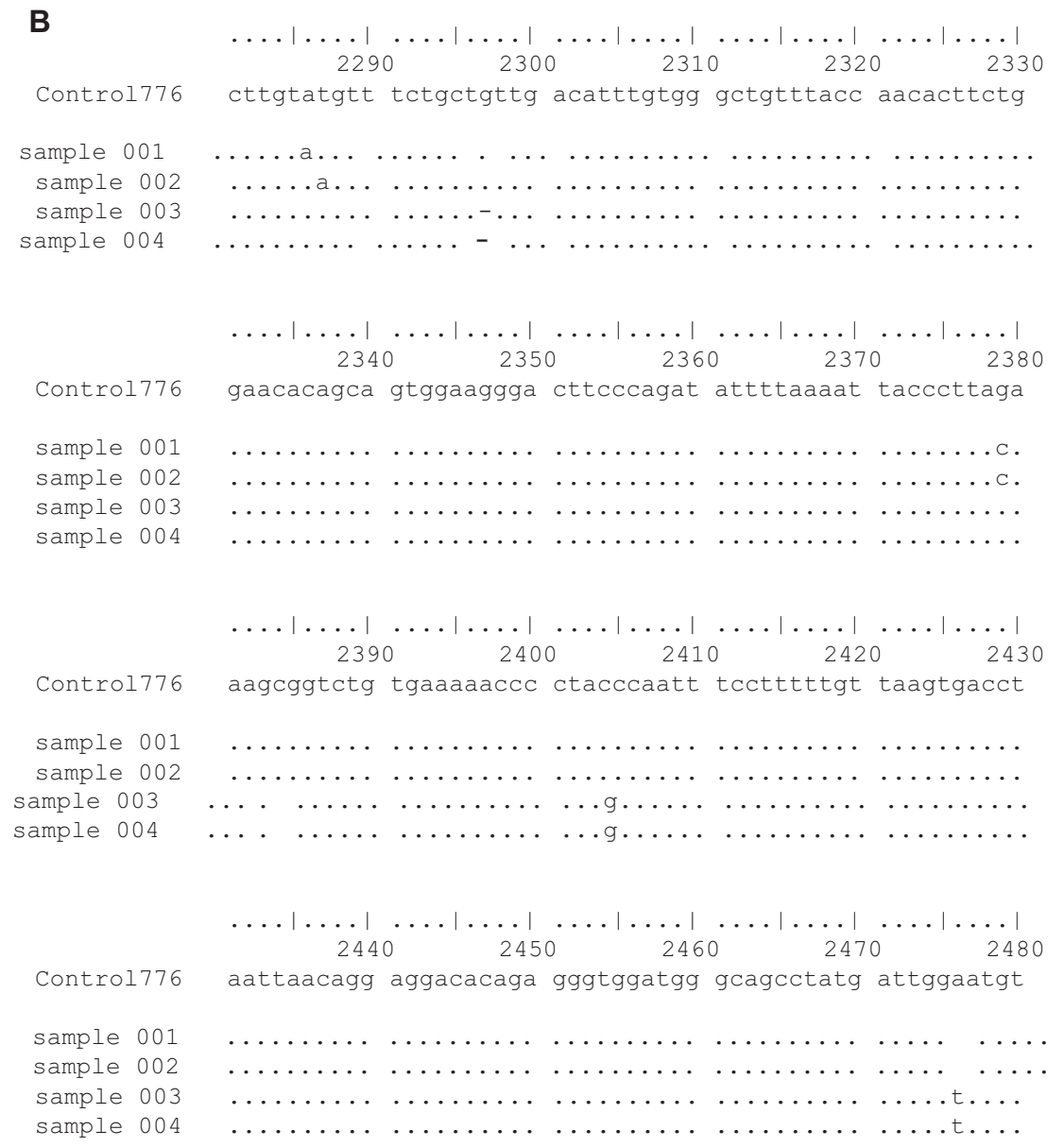

Figure 2. (Continued)

both assays were easily reproducible. In addition, the presence of polyomavirus DNA was determined on the simultaneously positive signal in 5 (in the case of SV40) or 2 (for other viruses) different PCR assays. Further investigation by sequencing revealed that the DNA detected were similar, but not identical to positive control sequences with respect to the partial LT-Ag and VP1 sequences (Figure 2). Variation in the DNA sequences argues strongly against laboratory contamination as an explanation for the finding.

Although SV40 infection has been previously reported in single renal and lung transplant patients $[8,9]$, to our knowledge it has not been described after multi-organ allografts. Organ-transplant recipients are at risk of polyomavirus infection. The role of $\mathrm{BKV}$ in polyomavirus-induced renal dysfunction is well established [10], but it is possible that SV40 infection also plays a role [9]. Our data support previous conclusions that SV40 infection is present in the human population and can cause infections in immunocompromised transplant recipients. Renal dysfunction after organ transplantation may be caused by cyclosporin toxicity, polyomavirus infection, or both factors. In our cases, the urinary shedding of SV40 DNA may suggest active replication of virus in kidneys in the setting of potent immunosuppression after multiple organ transplantation, and/or from the loss of renal epithelial cells or immune cells in the urine as a result of renal inflammation [8]. Therapeutic intervention, including reduction of immunosuppressive therapy in combination with antiviral therapy, improved renal function in both patients. To differentiate diagnosis for renal dysfunction, radiographic studies such as ultrasound and renal scan were performed to rule out the presence of an obstructive process or a vascular complication. Our data do not however establish a firm diagnosis of polyomavirus nephropathy as no renal biopsies were performed. This study adds support to a proposal from a previous study that kidney may represent a reservoir for SV40 infection. Co-infection of SV40 and BKV was detected, as observed previously [8].

In conclusion, SV40 infection can occur in immunocompromised patients indicating that SV40 is circulating in the community. SV40 could be a potential agent of kidney disorders in immunosuppressed patients. 
Further studies are needed to establish the frequency and clinical impact of SV40 in this patient group.

Declaration of interest: The authors report no conflicts of interest. The authors alone are responsible for the content and writing of the paper.

\section{References}

[1] Bergsagel DJ, Finegold MJ, Butel JS, Kupsky WJ, Garcea RL. DNA sequences similar to those of simian virus 40 in ependymomas and choroid plexus tumours of childhood. N Engl J Med 1992;326:988-93.

[2] Lednicky JA, Stewart AR, Jenkins JJ, Finegold, MJ, Butel JS. SV40 DNA in human osteosarcomas shows sequence variation among T-antigen genes. Int J Cancer 1997;72: 791-800.

[3] Barbanti-Brodano G, Sabbioni S, Martini F, Negrini M, Corallini A, Togon M. Simian virus 40 infection in humans and association with human disease: result and hypotheses. Virology 2004;318:1-9.
[4] Lednicky JA, Butel JS. Consideration of PCR methods for the detection of SV40 in tissue and DNA specimens. Dev Biol Stand 1998;94:155-64.

[5] Tognon M, Martini F, Iaccheri L, Cultrera R, Contini C. Investigation of the simian polyomavirus SV40 as a potential causative agent of human neurological disorders in AIDS patients. J Med Microbiol 2001;50:165-72.

[6] Abedi Kiasari B, Vallely PJ, Corless CE, Al-Hammadi M, Klapper PE. Age-related pattern of KI and WU polyomavirus infection. J Clin Virol 2008;43:123-5.

[7] Lopez-Rios F, Illei PB, Rushch V, Ladanyi M. Evidence against a role for infection in human mesotheliomas and high risk of false-positive PCR results owing to presence of SV40 sequences in common laboratory plasmids. Lancet 2004;364: $1157-66$.

[8] Li RM, Mannon RB, Kieiner D, Toskos M, Bynum M, Kirk $\mathrm{AD}$, et al. BK virus and SV40 co-infection in polyomavirus nephropathy. Transplantation 2002;74:1497-507.

[9] Milstone A, Vilchez RA, Geiger X, Fogo AB, Butel JS, Dummer S. Polyomavirus simian virus 40 infection associated with nephropathy in a lung-transplant recipient. Transplantation 2004;77:1019-24.

[10] Hirsch HH. Polyomavirus BK nephropathy: a (re-)emerging complication in renal transplantation. Am J Transplant 2002;2:25-30. 